\section{Outside eye on the hominid beat}

\section{Leonard Krishtalka}

Human Evolution: An Illustrated

Introduction.

By Roger Lewin.

Blackwell Scientific/W.H. Freeman:

1984. Pp. 104. Hbk \$22.36; pbk £6.80,

$\$ 14.95$.

PALAEOANTHROPOLOGY is familiar terrain to Roger Lewin. With Richard Leakey, he wrote Origins and People of the Lake, and he regularly covers the hominid beat, among other subjects, for Science. Not surprisingly, Human Evolution: An Illustrated Introduction is a testament to Lewin's expertise at science journalism. The writing is deft, the science lucid and the attitude no-nonsense.

All of the main characters in palaeoanthropology are here - Aegyptopithecus, Ramapithecus, Sivapithecus, the australopithecines and Homo - along with the basic plot: the origin and evolution of hominids, bipedalism, large brain size, tool technology and social structures. Lewin ties the fossil record, morphology and, as appropriate, the archaeology of the various taxa to reconstructions of their evolutionary relationships, palaeoecology and cultural adaptations. This core information occupies only 70 or so of the 99 pages. The remainder are devoted to first principles and to the auxiliary disciplines that impinge on hominid palaeontology: highlights of the evolution of life on Earth; primate origins, diversification and disper-

\section{How green was the Devonian valley?}

\section{Keith Allen}

Plant Life in the Devonian.

By Patricia G. Gensel and Henry N. Andrews.

Praeger: 1984. Pp.380. \$29.95, £32.95.

WITHIN palaeobotany, three areas of major and exciting evolutionary change can be distinguished. First, the origin and early evolution of life in the Precambrian; secondly, the rise of vascular land plants in the Upper Silurian and Devonian; and thirdly the origin and evolution of the angiosperms in the Lower Cretaceous.

In 1921 E.A. Newell Arber wrote a small book on Devonian floras. Arber's work supported the growing concept that Devonian land plants included the most primitive of vascular plants, and that this system was one of great evolutionary change, thereby encouraging an increasing number of research workers to study the sal; Neogene climates and geology; evolutionary theory; molecular-based phylogenies; taphonomy; ecological theory and more. Lewin also steers a clear and evenhanded course through such contentious issues as phyletic gradualism versus punctuated equilibrium, molecular versus palaeontological divergence clocks, the status of Australopithecus afarensis, sociobiology and so on.

This is not a personal work. Lewin is the journalist throughout, reporting the consensus and disagreements, and deferring in most instances to the conclusions of the principal investigators in each field. And the presentation is balanced: comprehensive yet concise, not overly technical for the general reader yet meaty enough for most students of human origins. The index is detailed and the selected bibliography adequate.

My one quibble concerns the illustrations. They complement and supplement the text, but curiously are not numbered; nowhere are they tied to the written material. Although most of the figures appear near the appropriate text, the usual intext references to figure so and so would have been helpful. Also, a few of the figure captions could be more explanatory, especially for those illustrations taken from technical research papers.

Over the past few years palaeoanthropology has matured into a vigorous multidisciplinary science. Lewin's Human Evolution is a concise primer on the subject which a wide variety of readers will find rewarding.

Leonard Krishtalka is Associate Curator in the Section of Vertebrate Fossils, Carnegie Museum of Natural History, Pittsburgh, Pennsylvania.

Devonian. All the ensuing activity was reflected in the enormous increase in species described, particularly during the past 25 years. But while books have appeared recently on both Precambrian life and angiosperm origins, one or two brief summaries apart there has been nothing on Devonian floras. This new volume by Gensel and Andrews partly satisfies the need for a detailed account of the subject.

Viewing the book as an entity, it seems to me that the authors couldn't decide whether to make it a monograph (though they indicate that it isn't) or a more general work. Much of the book (pp.36-314) contains good, readable descriptions in partial monographic form of selected species, together with discussions of heterospory and early seeds, and more general comments. An early chapter reviews pre-Devonian plants, particularly the microfloral evidence from the Upper Ordovician and Silurian, and later chapters briefly discuss palynology and Devonian floras.

In a volume which is assembled from sifting through an enormous number of papers there is bound to be some lack of balance, but the descriptive part of the book is unduly biased towards North American and western European species. Past research was indeed more or less confined to these areas, but Devonian floras have been recorded from the Soviet Union since the $1950 \mathrm{~s}$, and there has recently been considerable interest in China. The resulting descriptions are usually brief, but in some instances more could have been added at least for floristic comparisons; for example, no mention is made of the important genus Archaeopteris occurring in China. Also, in my opinion the authors have not placed enough importance on dispersed spores in the interpretation of Devonian floras. Reference is made to them only in passing in the discussion of heterospory, and in the in situ spore studies, yet the sculpture and construction in certain dispersed spores can confidently be used to give further information on age and geographic distributions of floras. Similarly, the section on Devonian floras is too short with the Middle Devonian landscape restricted to less than a page.

There are other points worth questioning. The authors refer to Cooksonia as the only undoubted vascular plant found in the Late Silurian, but the evidence is not conclusive that Cooksonia is a vascular plant. Even less so is Steganotheca, which they include within the vascular family Rhyniaceae, though earlier they mention it within the possible vascular plants. Why, one wonders, aren't Rhynia gwynne-vaughanii and Rhynia major given separate treatment, rather than being lumped under Rhynia, for the "xylem" of $R$. major is clearly very different from that in $R$. gwynne-vaughanii? Baragwanathia longifolia is included in the section on Lower and Middle Devonian fossils, when evidence now suggests that the lower Baragwanathia horizon is Upper Silurian (to be fair, this latest dating may have been published after the book went to press). It would, too, have been preferable for the descriptions of the rhyniophytes to have preceded rather than followed the trimerophytes; after all, they are less complex, and it seems likely that they gave rise to the trimerophytes. Finally, I am not convinced that a book on Devonian floras should include a detailed account of selected Lower Carboniferous seeds.

In this review I have concentrated on the shortcomings of the book, but, all in all, Gensel and Andrews have done well in compiling such a readable volume. Libraries will doubtless be the main market, though palaeobotanists and taxonomists will be pleased to own a personal copy. For the next edition the authors might consider including more information on palaeoecology, floras and evolutionary trends, which would broaden the potential readership to include third-year undergraduates.

Keith Allen is Senior Lecturer in Botany at the University of Bristol. 